\title{
Assessment of the load capacity of the anchorage system connecting the textured layer with the structural wall of large slab buildings in the lights of experimental research and FEM analysis
}

\author{
Jerzy K. Szlendak ${ }^{1}$, Agnieszka Jablonska-Krysiewicz ${ }^{1}$, and Dariusz Tomaszewicz ${ }^{2 *}$ \\ ${ }^{1}$ Faculty of Civil and Environmental Engineering, Bialystok University of Technology, Bialystok, \\ Poland \\ ${ }^{2}$ Higher School of Agribusiness in Lomza, Technical Faculty, Lomza, Poland
}

\begin{abstract}
The goal of the article is to compare the results obtained from experimental tests of a new type of anchoring, connecting the texture layer with the structural layer in external wall elements, used in large-panel construction with the results from FEM analysis. Two types of samples were subjected to experimental tests: single-layer uniform concrete and threelayer concrete with embedded point anchors and analogous samples with glued anchors. The test elements used C 12/15 and C 30/37 concrete, $12 \mathrm{~mm}$ diameter anchors, made of steel corresponding to the grade of stainless steel screws class 5.8, Sika Anchorfix-1 resin and XPS polystyrene. As for the three-layer samples, when testing, two forces were applied: tearing and shearing due to the detachment of the textured layer. The ANSYS program was used for numerical modelling of the analyzed samples. 3D models were built in which solid elements were used. For steel anchors, the material characteristics were taken as a two-line elastic-plastic reinforcement. The Drucker-Prager model was used in the concrete elements, the linear-elastic model was adopted for the resin, and the brittle model according to the linear-elastic fracture mechanics for the polystyrene.
\end{abstract}

\section{Introduction}

Strengthening the exterior walls of large-panel buildings is a necessity at this time. A number of faults resulting from both manufacturing defects and the progressive degradation of this type of buildings is described extensively in various articles and publications $[1,2,3,4,5]$. The problem of the durability of attaching the large panel texture layer is not, however, unambiguous. Technical condition of fasteners, i.e. "hangers" depend mainly on their coatings and what is the decisive factor of the use of the protection pill. With a view to the safe use of large-panel buildings and limiting the risk of detachment of the textured layer, the

*Corresponding author: Dariusz.Tomaszewicz@poczta.wsa.edu.pl 
detachment of which threatens the safety of people and property, works are carried out to extend the durability of fastenings of the textured layer through the use of bonded anchors.

\section{The course of research}

The samples were tested using the HYSDOZOK load feeding system. The test stand has been additionally equipped with auxiliary equipment to enable testing in the intended manner (Figure 1). In a single test, the reference load (vertical force) was set in accordance with the guidelines of standard [6], in this case $0.5 \mathrm{kN} / \mathrm{s}$. The shear load (horizontal force) of the top texture layer could only be asked due to the limitations of the actuator regulation in the case of three-layer samples, placed freely on the testing stand [Fig. 1, 2, 3, 4, 5 and 7].

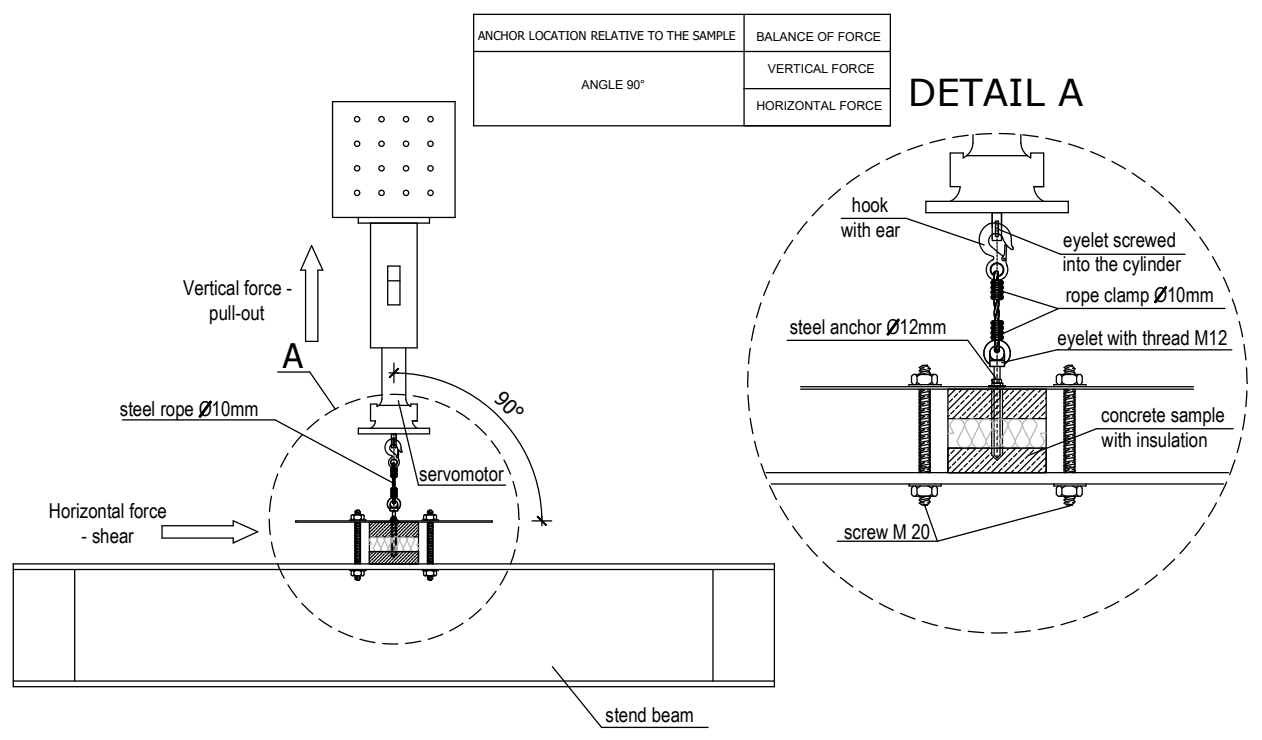

Fig. 1. Scheme and research procedures in the planned research.

The subject of the research were single and three-layer concrete samples. The study was conducted in two stages. The anchors anchored in the samples, at the variable depths of the anchor were examined first, while the second anchor was glued. The tests were carried out according to the following procedures. The previously prepared rope was screwed in the M12 anchor through the eyelet with an M12 internal thread, and then the actuator's ceiling was lowered so as to mount the rope hook in the M24 eye screwed through the double-sided thread into the actuator (in the M24 eye and the M22 actuator). 


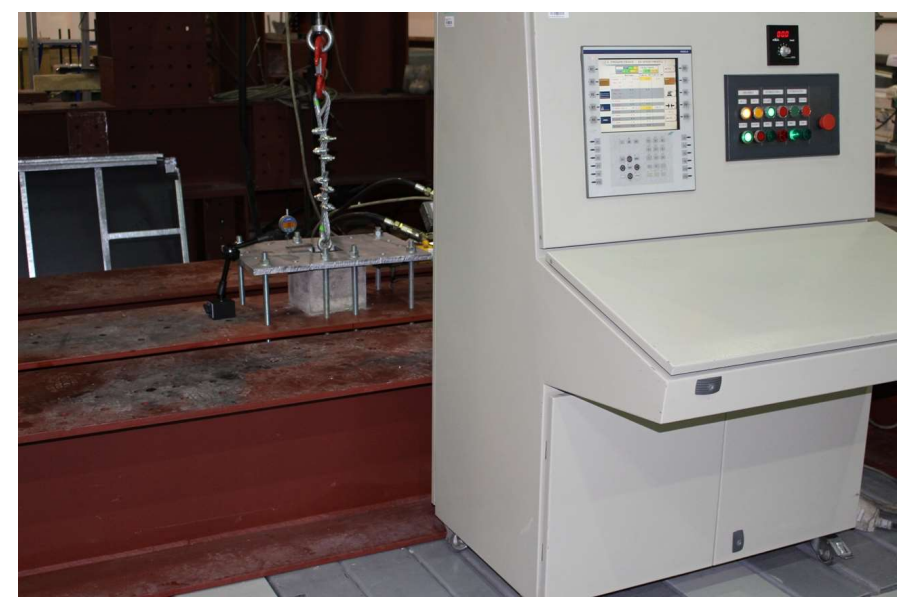

Fig. 2. The first stage of the preparation of the study.

The next step was the initial tension of the rope (Fig. 2). Then, under the steel plate in the vicinity of the hole cut in the sheet, whose dimension was the calculated diameter of the expected concrete cone, two steel rollers were placed in order to eliminate the friction force of the steel plate against the horizontal force.

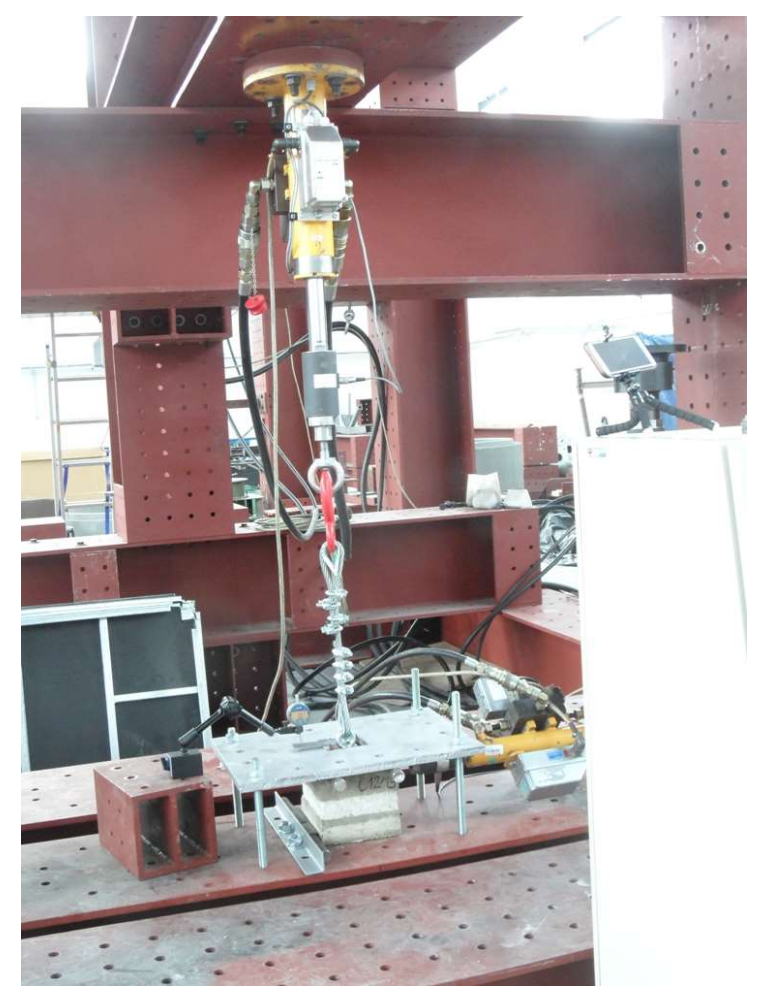

Fig. 3. The second stage of the preparation of the study.

The second stage of test preparation (fig. 3) consisted in the fact that the angle was bolted to the beam of the research stand and additionally a steel roll was placed between the angle and the sample to balance the horizontal force from the actuator. 


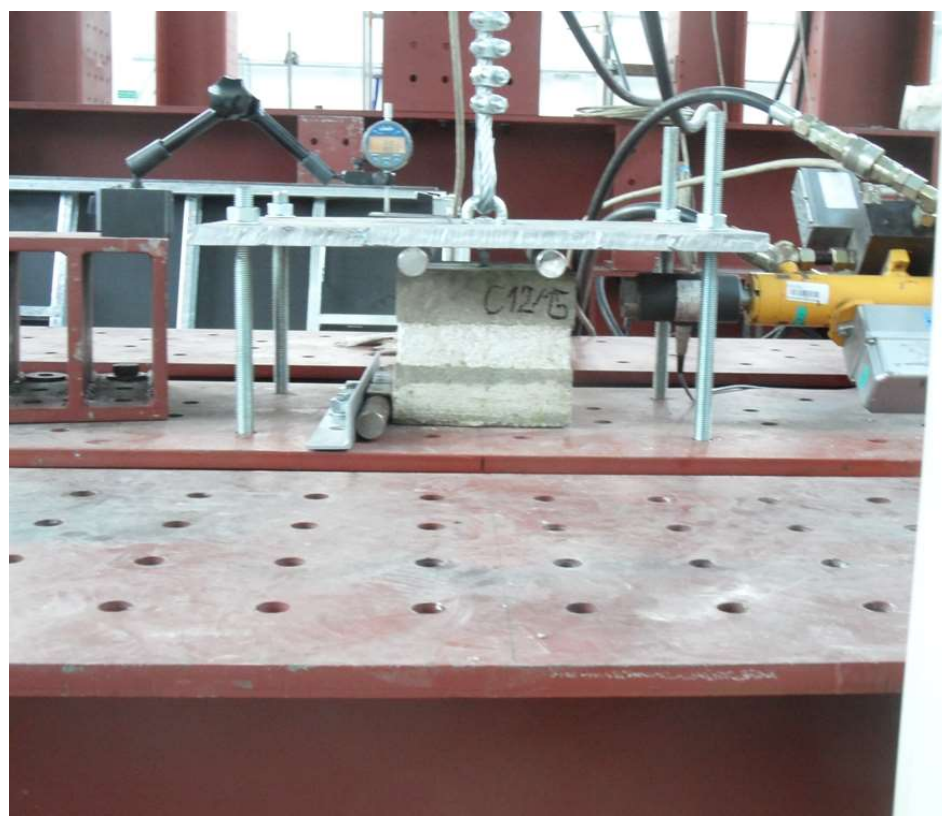

Fig. 4. View of the sample at the start of the test.

In the next step (Fig. 4) the machine was started. The simultaneous setting of vertical and horizontal load (fixed value) has begun. The limit value in the case of the described study was $15 \mathrm{kN}$ (Fig. 10).

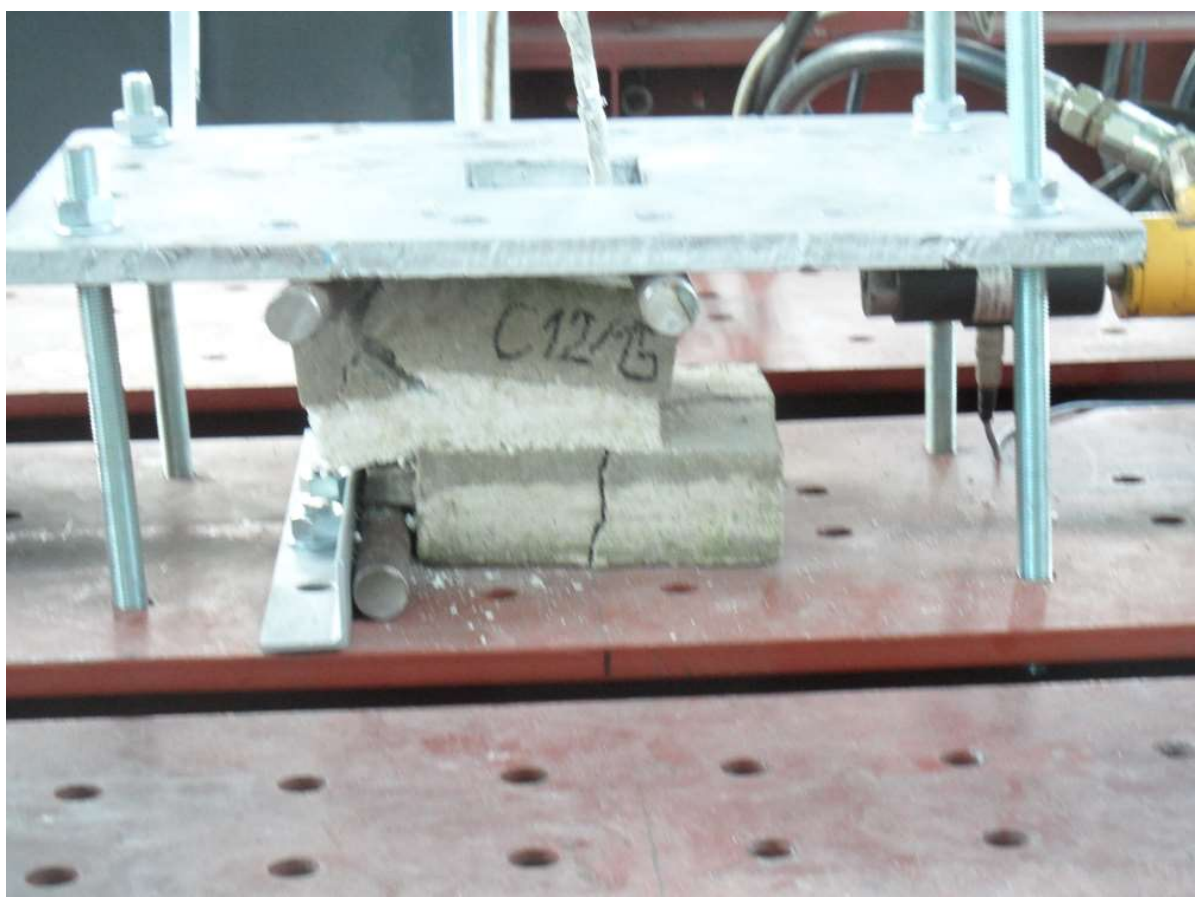

Fig. 5. View of the sample at the start of the test.

When the anchor was dislodged due to the load increase, the top texture layer and the insulation layer were displaced (Fig. 5). 


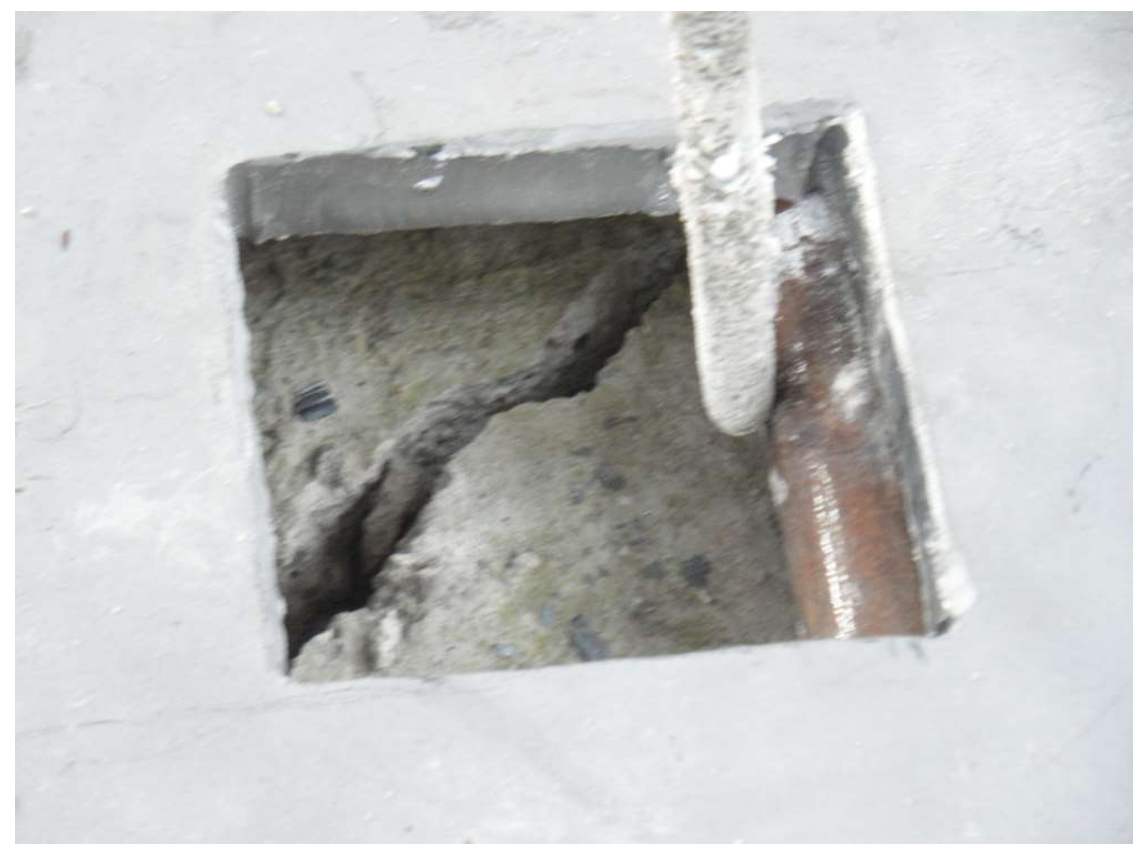

Fig. 6. View of the sample from above after pulling out the anchor.

The stage of pulling the anchor (fig.6) completed the test. Figure 7 shows the sample view after the test from behind the hydraulic cylinder.

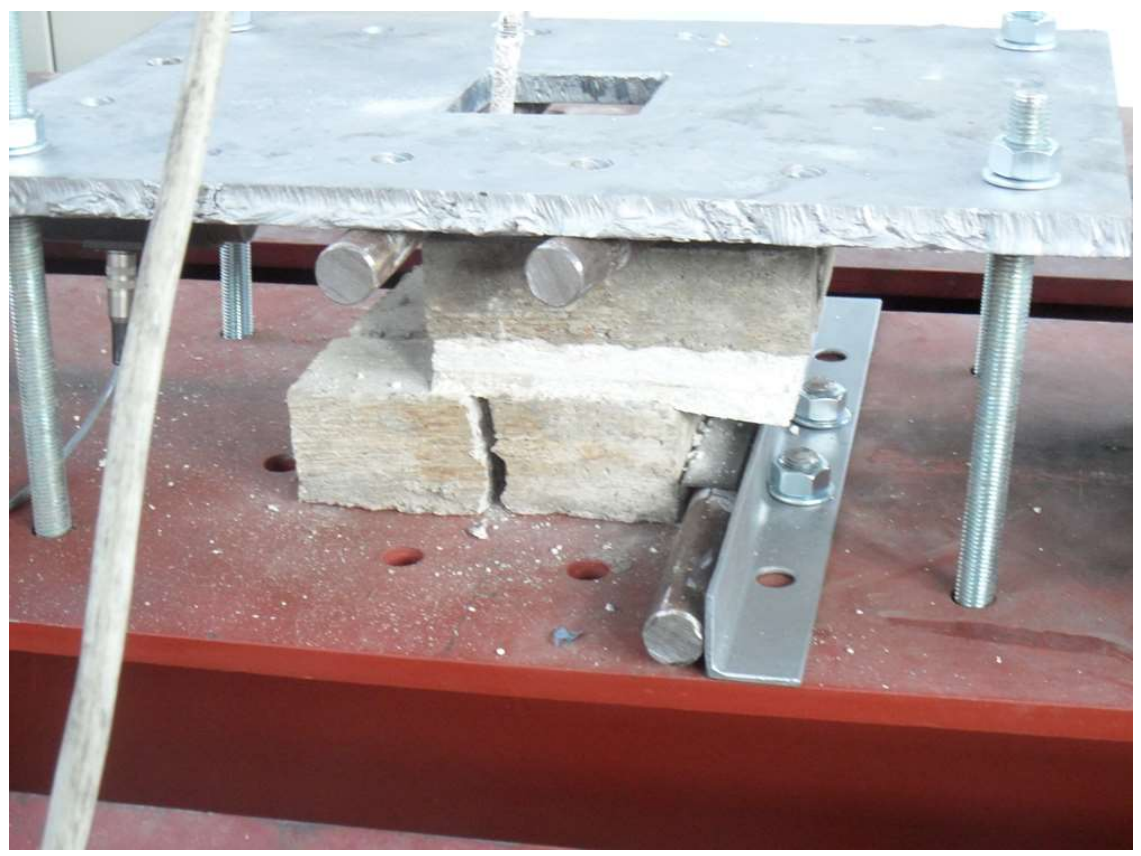

Fig. 7. Sample view from the other side.

In the illustrated test with a destructive force of $15 \mathrm{kN}$, a displacement value of $20 \mathrm{~mm}$ was obtained. 


\section{Summary of experimental research results}

Five samples were subjected to the experimental study. Three single layers, including two $\mathrm{C}$ $30 / 37$ classes and one C 12/15 class, as well as two three-layer samples made of C 12/15 concrete. Four anchors with a class of steel 5.8 were embedded in the formation of the samples, while one three-layer anchor was anchored at too low anchorage depth and the result of the test is unreliable. The test results are included in table 1.

Table 1. Test results.

\begin{tabular}{|c|c|c|c|c|c|c|c|}
\hline $\begin{array}{c}\text { Sam. } \\
\text { No. }\end{array}$ & $\begin{array}{c}\text { Sample } \\
\text { type }\end{array}$ & $\begin{array}{c}\text { Concrete } \\
\text { class }\end{array}$ & $\begin{array}{c}\text { Class of } \\
\text { steel } \\
\text { anchors }\end{array}$ & $\begin{array}{c}\text { Type of } \\
\text { resin }\end{array}$ & $\begin{array}{c}\text { Destr. } \\
\text { force, } \\
\text { kN }\end{array}$ & $\begin{array}{c}\text { Displac., } \\
\text { mm }\end{array}$ & $\begin{array}{c}\text { Type of } \\
\text { destruction }\end{array}$ \\
\hline 1 & single-layer & C $30 / 37$ & 5.8 & lack & 43,5 & 1,29 & $\begin{array}{c}\text { Breaking the } \\
\text { anchor }\end{array}$ \\
\hline 2 & single-layer & $\mathrm{C} 12 / 15$ & 5.8 & lack & 31,5 & 1,77 & $\begin{array}{c}\text { Pulling-out the } \\
\text { anchor }\end{array}$ \\
\hline 3 & $\begin{array}{c}\text { three-layer } \\
\text { (combined } \\
\text { pull-out } \\
\text { and shear } \\
\text { forces) }\end{array}$ & $\mathrm{C} 12 / 15$ & 5.8 & lack & 15,0 & 20,00 & $\begin{array}{c}\text { Pulling-out the } \\
\text { anchor }\end{array}$ \\
\hline 4 & $\begin{array}{c}\text { three-layer } \\
\text { (combined } \\
\text { pull-out } \\
\text { and shear } \\
\text { forces) }\end{array}$ & $\mathrm{C} 12 / 15$ & 5.8 & $\begin{array}{c}\text { Anchor } \\
\text { Fix-1 }\end{array}$ & $5 *$ & - & $\begin{array}{c}\text { Pulling-out the } \\
\text { anchor }\end{array}$ \\
\hline 5 & single-layer & $\mathrm{C} 30 / 37$ & 5.8 & lack & 44,0 & 2,69 & $\begin{array}{c}\text { Breaking the } \\
\text { anchor }\end{array}$ \\
\hline
\end{tabular}

* too shallow fixing of the anchor in the construction layer.

For the obtained test results, the dependencies of force increase (or two forces) on displacement were presented in graphical form in Figures 8-11.

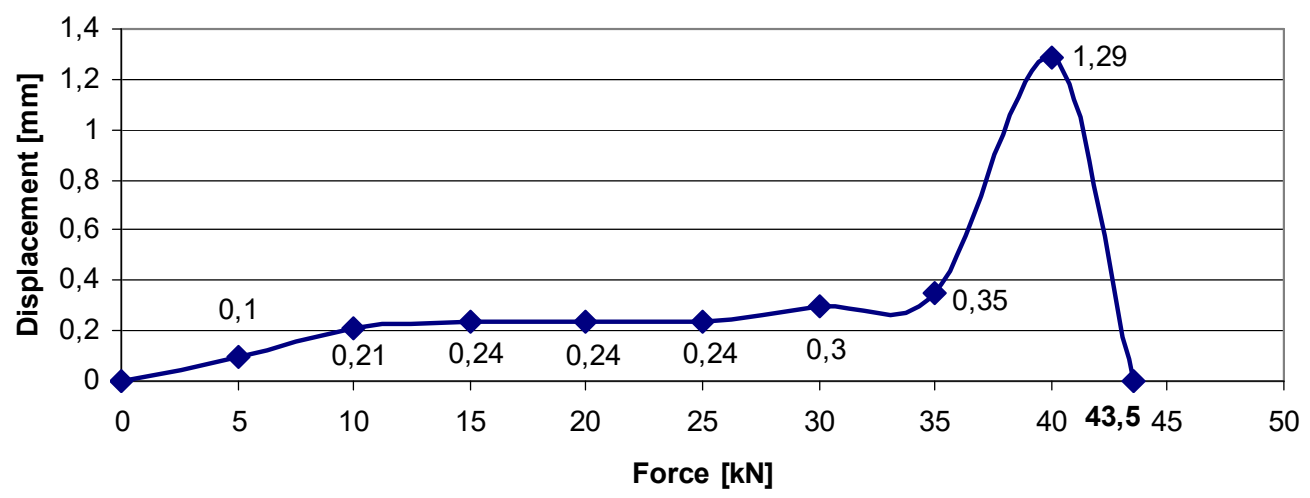

Fig. 8. Dependence force-displacement for a single-layer sample of C $30 / 37$ concrete.

The reading of the results was carried out in steps of $5 \mathrm{kN}$ with a uniform increase in the breaking force of $0.5 \mathrm{kN} / \mathrm{s}$ and shear force in the case of three-layer samples individually applied load equal to $1.4 \mathrm{kN}$ corresponding to a load of $1 \mathrm{~m} 2$ of the textured layer surface. 


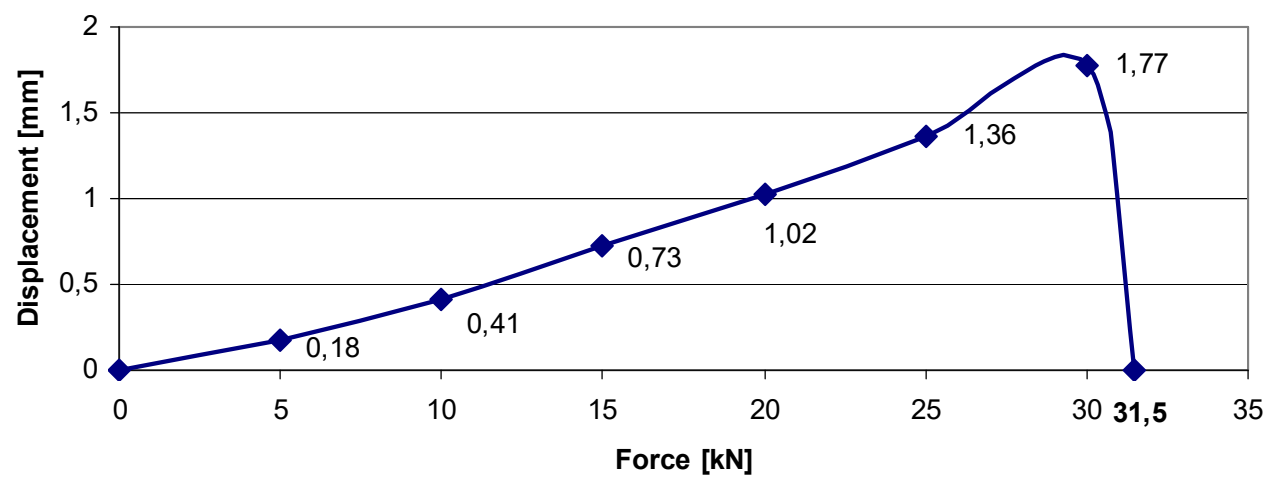

Fig. 9. Dependence force-displacement for a single-layer sample of C $12 / 15$ concrete class.

Attention should be paid to clearly higher values (Fig. 10) than is the case in other graphs

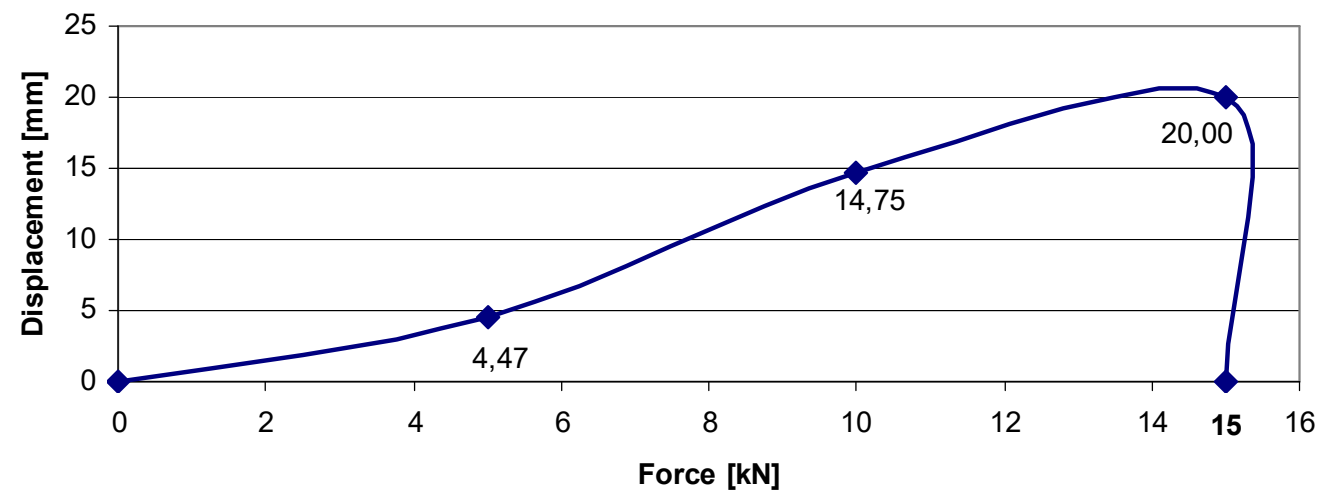

Fig. 10. Dependence force-displacement for a single-layer sample of C 12/15 concrete class.

Attention is also drawn to the fact that the results are reproducible in the case of samples No. 1 and No. 5 (Fig. 8 and Fig. 11).

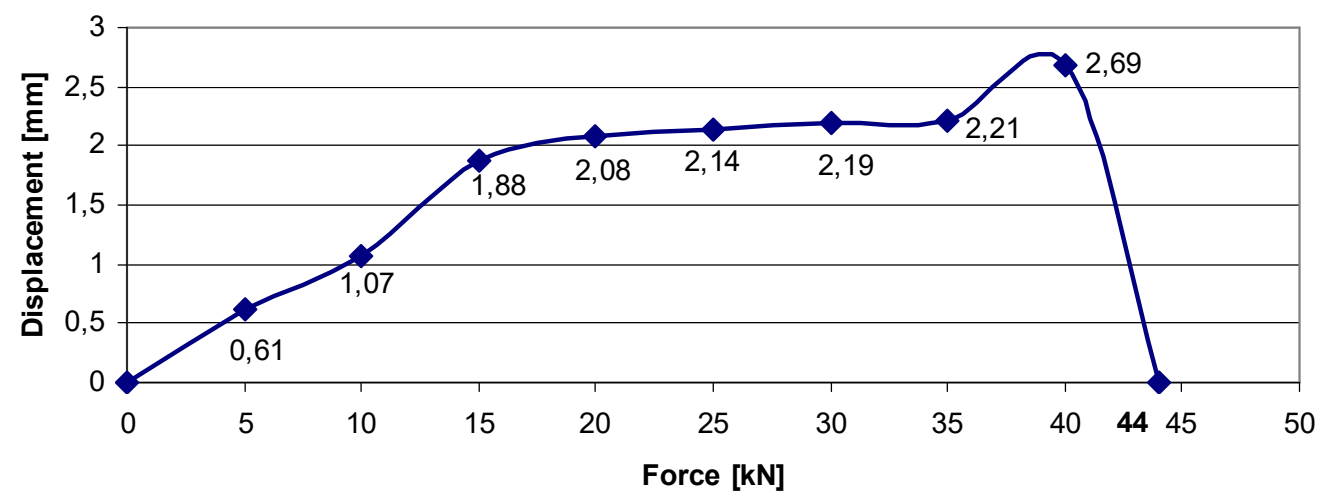

Fig. 11. Dependence force-displacement for a single-layer sample of C 30/37 concrete. 


\section{Comparison of the obtained results with the FEM analysis}

The single-layer model were analyzed. These models were chosen due to the fact that the effective anchorage depth concerns only the structural layer.

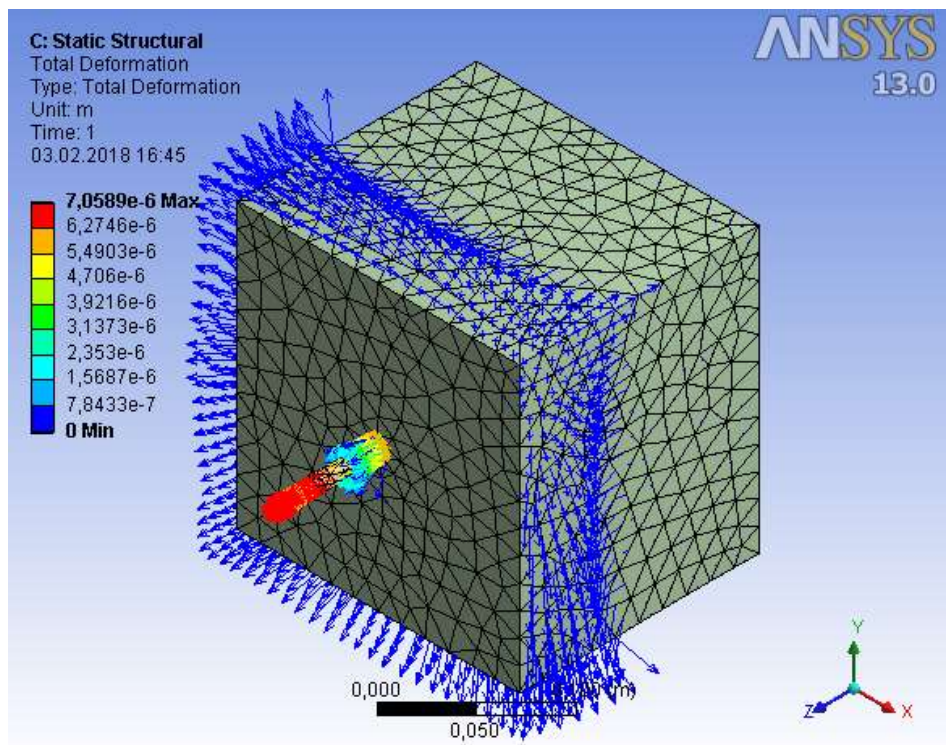

Fig. 12. Deformation of the first sample under test after load loading in the program.

The numerical analysis of the experimentally tested samples was carried out in the ANSYS program. The 3D model was built of solid elements (Fig. 12.). For steel anchors, two-line elastic-plastic characteristics with material reinforcement were adopted, in the concrete element the Drucker-Prager model was used. Material parameters of the D-P model are: concrete deformation module $\mathrm{E}=200 \mathrm{MPa}$, Poisson ratio $v=0.20$, internal friction angle $\varphi=45^{\circ}$ and cohesion $\mathrm{c}$ as a value equal to concrete tensile strength (for concrete $\mathrm{C} 12 / 15 \mathrm{c}=$ 0.73 , for concrete $\mathrm{C} 30 / 37 \mathrm{c}=1.33$ ). Additionally, according to the angle of internal friction, the angle of dilation $\Psi=\varphi-30^{\circ}=15^{\circ}$ was estimated. The D-P model is based on the principles of triaxial stretching. Smooth plasticity surface of the D-P model depends on the average effective stress $\boldsymbol{\sigma}_{\mathbf{m}}$ and forms a cone in the space of main stresses.

Table 2. Parameters of cooperation between concrete and steel obtained from research and FEM analysis.

\begin{tabular}{|c|c|c|c|c|}
\hline Type & $\begin{array}{c}\text { von-Mises } \\
\text { Stress }\end{array}$ & Strain energy & $\begin{array}{c}\text { von-Mises Elastic } \\
\text { strain }\end{array}$ & Total deformation \\
\hline Minimum & $3514,3 \mathrm{~Pa}$ & $3,2785 \mathrm{e}-010 \mathrm{~J}$ & $1,1714 \mathrm{e}-007 \mathrm{~m} / \mathrm{m}$ & 0 \\
\hline Maximum & $1,3574 \mathrm{e}+008 \mathrm{~Pa}$ & $8,6164 \mathrm{e}-004 \mathrm{~J}$ & $7,9027 \mathrm{e}-004 \mathrm{~m} / \mathrm{m}$ & $7,0589 \mathrm{e}-006 \mathrm{~m}$ \\
\hline $\begin{array}{l}\text { Minimum } \\
\text { Occurs On }\end{array}$ & \multicolumn{3}{|c|}{ steel } & concrete \\
\hline $\begin{array}{l}\text { Maximum } \\
\text { Occurs On }\end{array}$ & \multicolumn{3}{|c|}{ steel concrete } & steel \\
\hline
\end{tabular}

In the table 3 summarizes and compares the results of laboratory tests with the results of the MES analysis. 
Table 3. Comparison of results of single-layer samples with MES analysis

\begin{tabular}{|c|c|c|c|c|c|}
\hline $\begin{array}{c}\text { Angle of } \\
\text { anchorage }\end{array}$ & $\begin{array}{c}\text { Sample } \\
\text { type }\end{array}$ & $\begin{array}{c}\text { Concrete } \\
\text { class }\end{array}$ & $\begin{array}{c}\text { The result of } \\
\text { laboratory test, } \\
\text { kN }\end{array}$ & $\begin{array}{c}\text { The result of } \\
\text { computer } \\
\text { simulation, kN }\end{array}$ & $\begin{array}{c}\text { Difference } \\
{[\%]}\end{array}$ \\
\hline $90^{\circ}$ & single-layer & C $30 / 37$ & 43,5 & 42,0 & 3,4 \\
\hline $90^{\circ}$ & single-layer & C $12 / 15$ & 31,5 & 27,0 & 14,3 \\
\hline $90^{\circ}$ & single-layer & C $30 / 37$ & 44,0 & 42,0 & 4,5 \\
\hline
\end{tabular}

Attention should be paid to the distance between the differences in the concrete classes $9.8-10.9 \%$. In the case of mass elements made of concrete C $30 / 37$, the average difference was $3.95 \%$, with the highest difference of $4.5 \%$. In comparison with the numerical results of tests, the steel anchor-concrete connection was adopted as glued, without additional contact elements.

\section{The direction of further research}

Currently, preparations are being made to examine oblique anchors in a manner not practiced so far. The tests would be carried out according to the diagrams shown in Figures 13, 14 and 15.

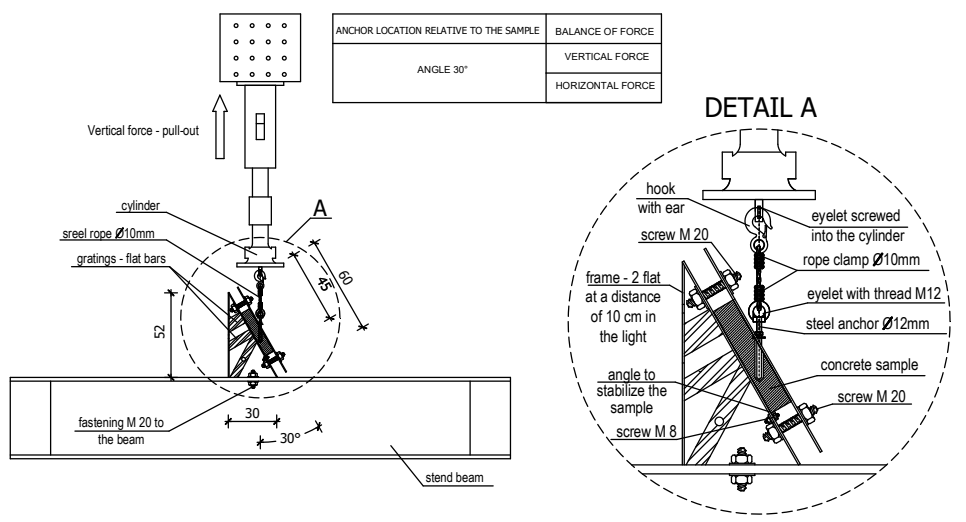

Fig. 13. Scheme of the test bench for oblique anchors at an angle of $30^{\circ}$.

To the beam of the test stand, special racks, set for the desired test angle, should be mounted for this type of examination. Blocking the sample before slipping through an angle bolted into M8 bolts into shoulder cuts. 


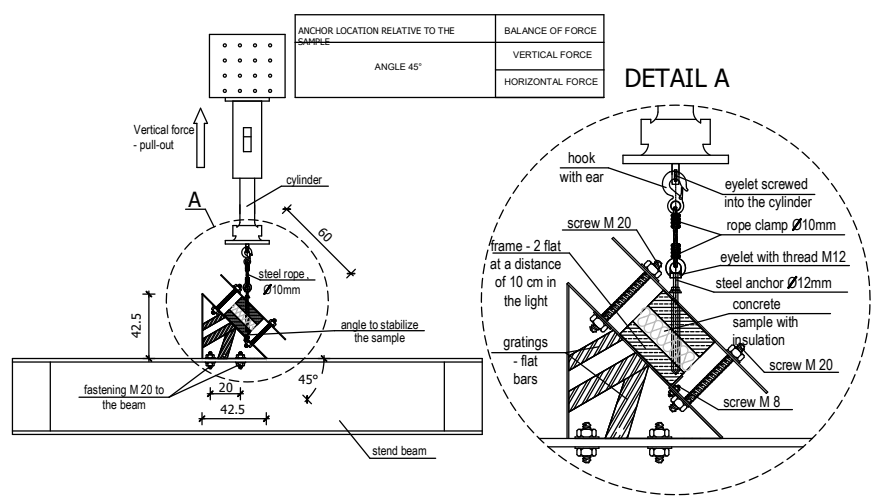

Fig. 14. Scheme of the test bench for oblique anchors at an angle of $45^{\circ}$.

The mounting hook, rope and eyes screwed onto the anchor and through the double-sided thread to the actuator had to meet load capacity parameters to check this type of connections.

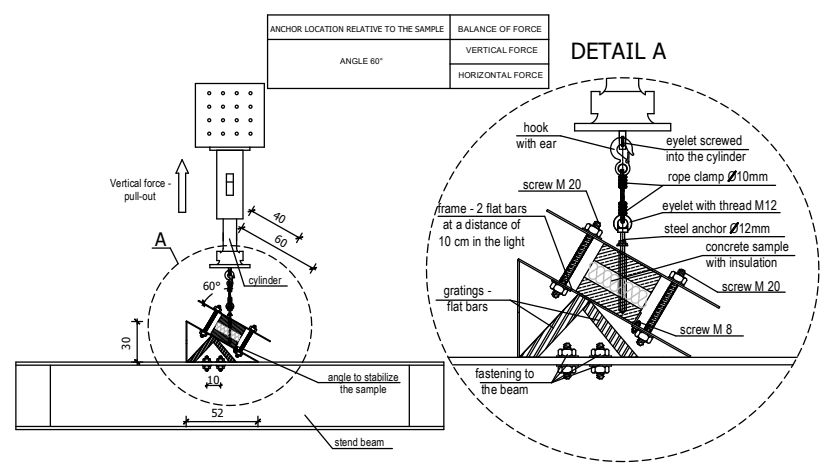

Fig. 15. Scheme of the test bench for oblique anchors at an angle of $60^{\circ}$.

\section{Conclusions}

The purpose of the tests is to experimentally check the impact of the tearing and shearing force on the durability of the fasteners and to determine their value at the boundary point (destruction of joints). Conducting these studies will also answer the question of the role of oblique anchors in strengthening the walls of three-layer large-panel buildings. The adhesion of the anchorages will also be determined depending on the parametric selection of the resin.

The paper was prepared at Bialystok University of Technology within a framework of the S/WBiIŚ/2/2017 project sponsored by Ministry of Science and Higher Education.

\section{References}

1. P. A. Prieto-Muñoz, H. M. Yin. R. B. Testa,An Elastic Analysis That Predicts the PullOut Capacity of Adhesive Anchors, Materials Science and Engineering 10, 1-10 (2010)

2. M. Bajer, J. Kala, J. Barnat, Modeling chemical anchor placed in concrete using different FEM systems, The 9th International Conference "MODERN BUILDING MATERIALS, STRUCTURES AND TECHNIQUES”, Brno University of Technology, (2007)

3. M. Kijania, Metody wyznaczania wartości naprężenia przyczepności pomiędzy betonem a stala zbrojeniowa, Przegląd Budowlany 6/2015, 38-42, (2015) 
4. U. M. Mahran, Theoretical Study For Bond Between Reinforcement Steel And Concrete, IJSBAR, Vol. 12, No. 1, 93-192 (2013)

5. A. Spada, P. Rizzo, G. Giambanco, Elastoplastic Damaging Model for Adhesive Anchor Systems. II: Numerical and Experimental Validation, JOURNAL OF ENGINEERING MECHANICS, 862-876 (2011)

6. PN-EN 12504-3:2006, Research of concrete in structures - Part 3: Determination of pull-out strength. (in Polish) 